\title{
Pushed monocanalicular intubation versus probing as a primary management for congenital nasolacrimal obstruction
}

This article was published in the following Dove Press journal:

Clinical Ophthalmology

7 September 2016

Number of times this article has been viewed

\section{Emad Abdelaal Elsawaby Rania Assem El Essawy Sameh Hassan Abdelbaky Yomna Magdy Ismail}

Department of Ophthalmology, Faculty of Medicine, Cairo University, Cairo, Egypt
Correspondence: Sameh Hassan Abdelbaky

Department of Ophthalmology, Faculty of Medicine, Cairo University, Abdelaziz al Seoud st. Manial, Cairo, Egypt

Tel +20 I2 2106 I228

Email samhassan76@gmail.com
Purpose: Evaluation of efficiency, complications, and advantages of pushed monocanalicular intubation using Masterka ${ }^{\circledR}$ tube versus simple probing in patients with congenital nasolacrimal duct obstruction (CNLDO).

Patients and methods: This is a case-controlled study that included 60 eyes (of 53 patients); 30 eyes underwent probing and 30 eyes intubation using the Masterka tube as a primary treatment for CNLDO. The children were aged between 6 months and 36 months at the time of surgery, with no previous nasolacrimal surgical procedure, and had one or more of the following clinical signs of nasolacrimal duct obstruction: epiphora, mucous discharge, and/or increased tear lake.

Results: We defined success by absence of epiphora, mucous discharge, or increased tear lake 1 month after tube removal. The overall success rate in the probing group was $80 \%$, while it was $83.3 \%$ in the intubation group.

Conclusion: Pushed monocanalicular intubation is an effective method for treatment of CNLDO; it requires only mask inhalation anesthesia and could be considered as an appropriate alternative procedure with imperceptible complications.

Keywords: epiphora, probing, intubation, monocanalicular, nasolacrimal

\section{Introduction}

Congenital nasolacrimal duct obstruction (CNLDO) occurs in up to $70 \%$ of neonates at delivery. However, only $6 \%-20 \%$ of all neonates have symptoms, because the obstruction usually resolves spontaneously before lacrimal secretion begins. ${ }^{1}$ The main presentation of nasolacrimal obstruction is watering (epiphora) and mucopurulent discharge observed from the first month of life. This usually occurs in only one eye, although both eyes may be affected in up to $20 \%$ of cases. ${ }^{2}$

The treatment of CNLDO includes observation, topical antibiotics with tear duct massage, and surgical interventions ranging from simple probing to more invasive procedures, such as stent intubation and dacryocystorhinostomy. There is marked controversy regarding the treatment - both conservative and surgical - of CNLDO, mainly due to a literature based on lower levels of evidence such as case reports, expert opinion, and noncontrolled mainly retrospective studies. ${ }^{3,4}$ Higher levels of evidence such as systematic reviews, meta-analyses, and randomized controlled studies are lacking in this clinical area. ${ }^{5}$

Lacrimal system intubation has become a prominent method in the management of refractory cases of CNLDO and in those resistant to probing. ${ }^{6-8}$ Increased experience 
with the technique and the introduction of various intubation techniques such as monocanalicular intubation (MCI) have led to choosing intubation as a primary procedure for nasolacrimal duct obstruction in younger children. Success rates from $79 \%$ to $96 \%$ have been reported for intubation as a primary procedure in retrospective case series. ${ }^{6.8}$ However, the use of these stents requires intubation anesthesia and is associated with a longer operative time and a consecutive higher cost of operation.

We conducted a prospective randomized study to assess the use of the new, easily introduced pushed MCI in comparison to simple probing for primary management of CNLDO.

\section{Patients and methods}

This study included 60 eyes randomly divided into two groups. Patients were selected from the outpatient Ophthalmology Clinic of Abureesh Specialized Pediatric Hospital, Cairo University. The protocol was revised and approved by Cairo University Ophthalmology Ethical Committee; all parents/ guardians signed an informed consent before the initiation of the procedure and gave consent to publish their information and images in the study. The study was carried out from September 2012 to December 2013. Patients aged $<3$ years with membranous CNLDO and complaining of epiphora with or without discharge with no previous intervention and no associated craniofacial anomalies were included.

Patients were randomly divided into groups A and B. Randomization was done through random allocation sequence (chit method).

Group A: 30 eyes underwent simple probing of nasolacrimal duct.

Group B: 30 eyes underwent insertion of Masterka ${ }^{\circledR}$ tube in addition to initial probing.

Complete ophthalmological evaluation was done with detailed history taking. The function of the lacrimal pathway was evaluated by:

- History of onset of symptoms, severity of lacrimation, symptoms of repeated infections such as discharge and itching, history of previous medical therapy, or nasolacrimal massage.

- Clinical examination included evaluation of the conjunctival sac and tear film, punctual and medial canthus inspection, and regurge test.

- Modified fluorescein dye disappearance time: a drop of fluorescein is administered on the conjunctiva and the amount of dye present in the conjunctival sac after 5 minutes is recorded.

The history and the modified fluorescein dye disappearance time were considered to be the major end points.

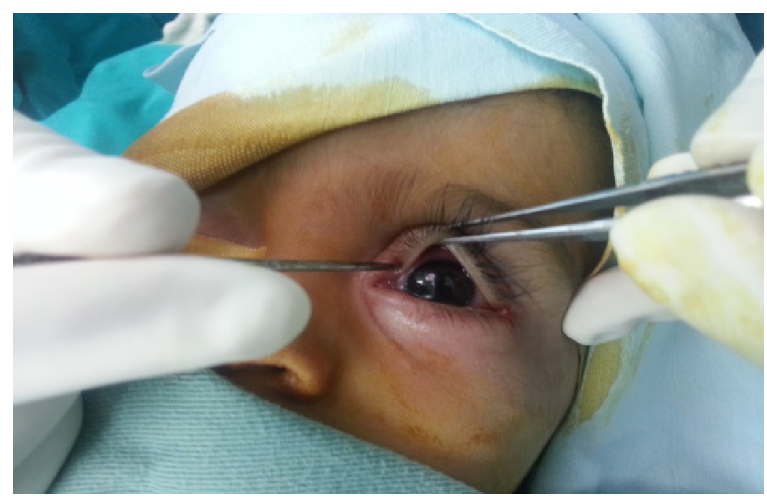

Figure I Punctal dilatation.

\section{Surgical techniques}

Under mask anesthesia, probing of the canaliculi and nasolacrimal duct was used to assess the anatomy and functional status of the nasolacrimal pathway, and to exclude cases other than those with membranous obstruction at the level of Hasner's valve.

The upper punctum was dilated with a punctal dilator (Figure 1). A small lacrimal probe was then used initially to probe the lacrimal passage followed by progressively larger probes if possible.

After the probe enters the lacrimal sac (as signaled by the presence of a "hard stop"), it was rotated superiorly, with the body of the probe against the eyebrow. Once the probe was rotated to the level of the supraorbital notch at the superior orbital rim, it was guided down the nasolacrimal duct, directed slightly posteriorly and laterally as it is advanced (Figure 2). Any significant resistance at this point was not overcome with force; instead, the probe was withdrawn and the procedure repeated.

In the other group, the same procedure was performed then the tube was inserted. The Masterka (FCI Ophthalmics Inc., Pembroke, MA, USA) pushed monocanalicular silicone

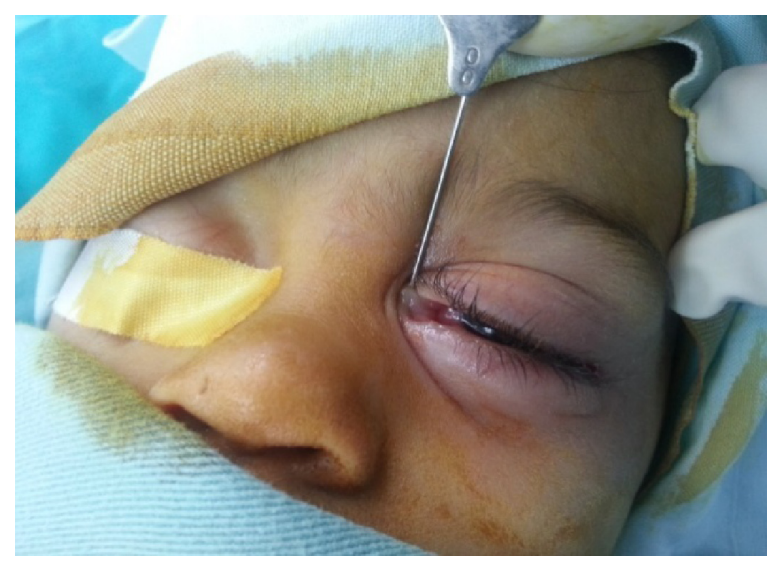

Figure 2 Initial probing. 


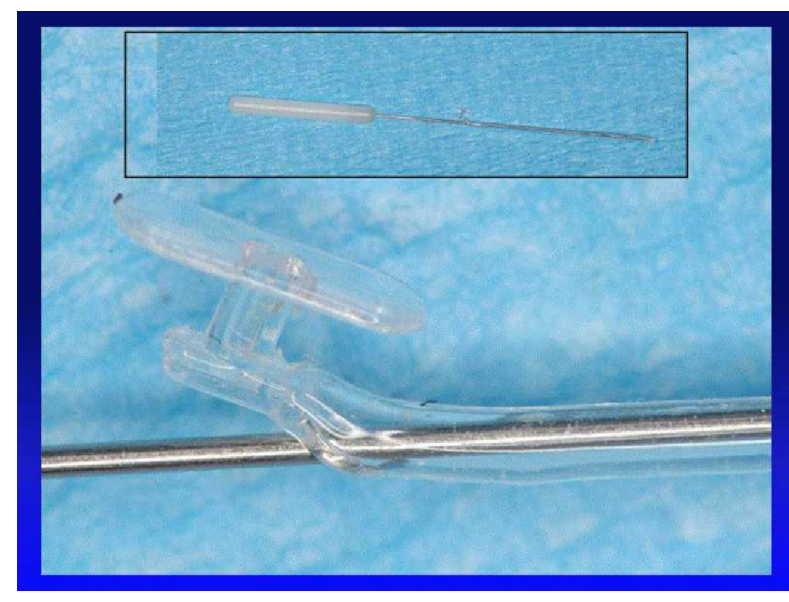

Figure 3 Masterka ${ }^{\circledR}$ tube.

intubation set is a pushed lacrimal intubation stent with anchoring plug for punctal fixation; the metallic guide is located inside the silicone tube, which is available in sizes of $30 \mathrm{~mm}, 35 \mathrm{~mm}$, and $40 \mathrm{~mm}$. It has the same principle of venous catheters (Figure 3).

The metallic probe was inserted till the site of obstruction is reached and the punctual position is noted on the probe (Figure 4). The stent was chosen so that it measures $\sim 5 \mathrm{~mm}$ longer than the measured distance on the probe (Figure 5). The silicon tube was then inserted (Figure 6) till the plug is firmly held in contact with the punctum before removal of the metallic guide (Figure 7). The probe was then withdrawn along the main axis of the lacrimal duct and the tube plug secured in place (Figure 8).

Patients of both groups were given combined antibiotic steroid eye drops for 5 days. Patients were followed up at 1 week, 2 weeks, and 1 month. Removal of the Masterka tube was done after at least 3 weeks. The stent was removed as an office procedure with a forceps instrument by pulling on

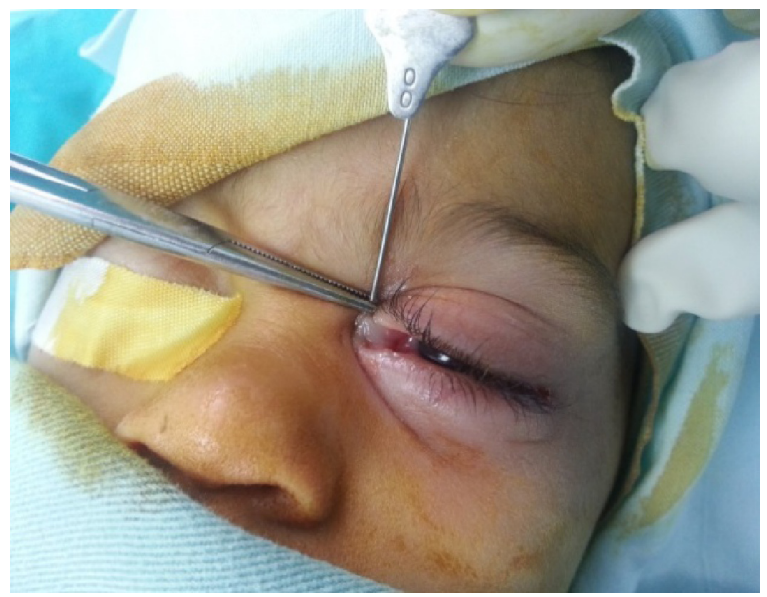

Figure 4 Marking length on probe.

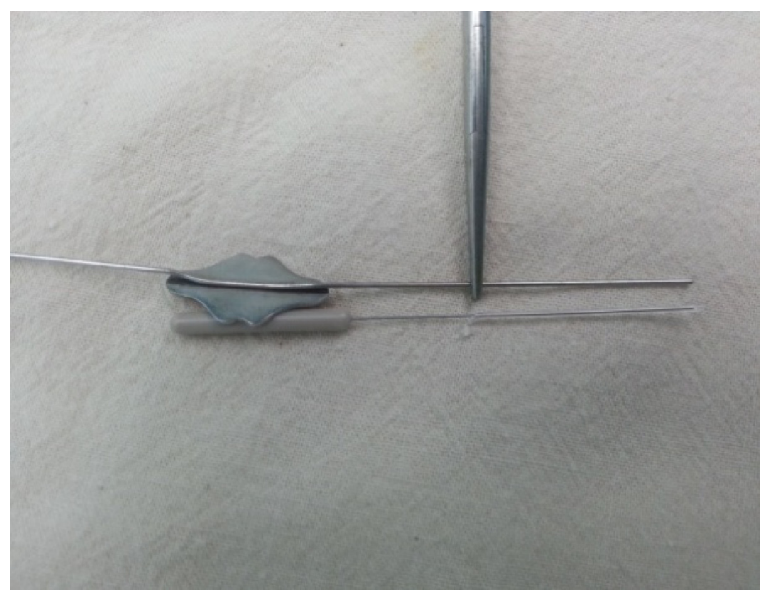

Figure 5 Choice of appropriate tube.

the collaret. This removal is painless and does not require any anesthetic.

The results were evaluated according to a modified Munk's scoring system. Cases with a score of 0 or 1 after 3 months from surgery were considered successful (Table 1).

All data were statistically analyzed using Microsoft excel software program with analyze it software add-in. Descriptive statistical analysis was first performed. For categorical variables (eg, sex) percent distribution was used. For other contentious variables (eg, age), frequency distribution, mean, median, range, and standard deviation were used. Values were then expressed as mean \pm standard deviation.

Comparison between the patient's two groups was made using Student's $t$-test for independent samples for continuous variables and chi-square test for categorical variables. Liner regression analysis was used to assess the correlation between continuous variables. For all statistical tests, a $P$-value of $\leq 0.05$ was considered to be of statistical significance.

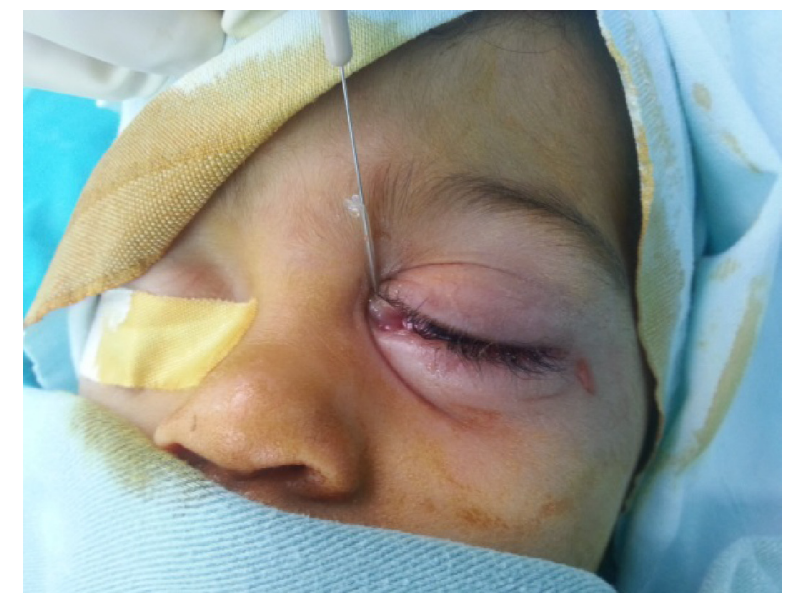

Figure 6 Masterka insertion. 


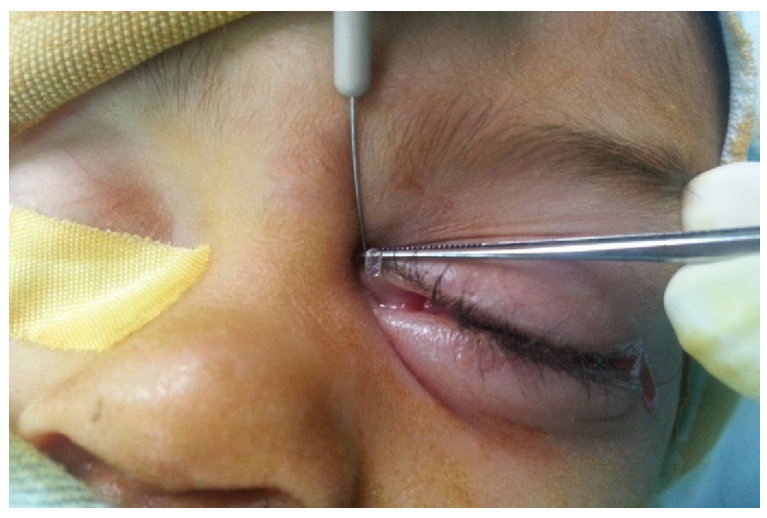

Figure 7 Removal of wire guide.

\section{Results}

Group A: 30 eyes of 23 patients, 12 females and eleven males (average age, 16 months; range, 7-34 months), underwent simple probing. Success was observed in 24 eyes, $80 \%$ with an average follow-up of 14 weeks. One patient had epistaxis for 2 days, one patient was found to have upper punctual atresia, and one patient had lower canalicular obstruction. Six cases (20\%) required further intervention, with $63.3 \%$ of cases showing complete resolution of symptoms (grade 0 ).

Group B: 30 eyes of 27 patients, 13 females and 14 males (average age, 14.85 months; range, 7-30 months), underwent Masterka intubation. Success was observed in 25 eyes, $83.3 \%$ with an average follow-up of 16 weeks. The tube plug was cut in two patients but the tubes stayed still in place. One patient had corneal ulcer 1 week after surgery, the cause of which was unknown and it healed with proper treatment leaving no complications. Two patients had epistaxis for 2 days. Six patients had their tubes removed after $>2$ months and five cases $(16.7 \%)$ required further intervention, with $73.3 \%$ of cases showing complete resolution of symptoms (grade 0 ).

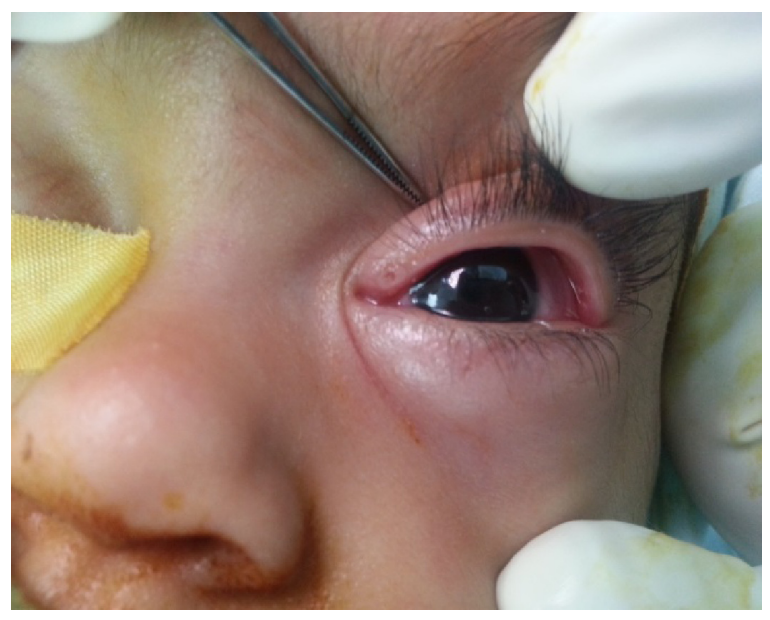

Figure 8 Anchoring plug in place.
Table I Modified Munk's scoring system for epiphora9

\begin{tabular}{ll}
\hline Findings & Grade \\
\hline No epiphora or tear lake & 0 \\
$\quad$ No dye & \\
Occasional epiphora $<5$ times drying/day or increased tear lake & \\
$<25 \%$ dye present after 5 minutes & I \\
Epiphora 5-10 times drying/day & 2 \\
$25 \%-50 \%$ dye present after 5 minutes & \\
Epiphora 10 times drying/day & 3 \\
$50 \%-75 \%$ dye present after 5 minutes & \\
Frequent epiphora $>10$ times drying/day & 4 \\
$75 \%-100 \%$ dye present after 5 minutes & \\
\hline
\end{tabular}

However, the difference between the success rates in the two groups was statistically insignificant $(P>0.5)$.

Follow-up of cases who underwent probing showed a higher success rate of $86 \%$ in the first week compared with $80 \%$ at 3 months follow-up with $63.3 \%$ of cases showing complete resolution of symptoms (grade 0 ), while follow-up showed progressive improvement of symptoms in patients who underwent intubation, the success rate in those during the first week was $83.3 \%$ and increased to $86.6 \%$ at 2 months. Cases that showed complete resolution of symptoms (grade 0 ) comprised $26.7 \%$ in the first week, which then increased to $73.3 \%$ by the end of the follow-up (Figure 9 ).

\section{Discussion}

There is comprehensive literature advising treatments for CNLDO, opinions have diverged as to the appropriate treatment regarding nature and timing. In our study, we compared the pushed MCI by Masterka stent as a primary treatment for congenital nasolacrimal obstruction versus simple probing.

Our study included 60 eyes of 50 patients with CNLDO between the ages of 6-36 months, 30 eyes did primary MCI with Masterka and 30 eyes did primary probing. The overall success rate in the intubation group was $83.3 \%$, whereas in the probing group it was $80 \%$. However, the difference in

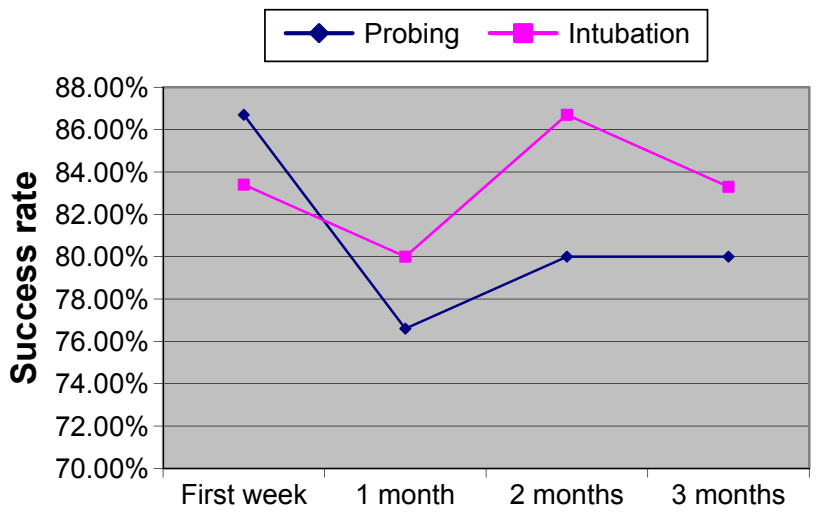

Figure 9 Progression of success rates through the follow-up period in the two groups. 
the success rates between the two groups was not statistically significant ( $P$-value of 1$)$.

We found success in the probing group in $80 \%$ of cases (24 cases). Studies of primary surgical management have found probing to be also successful in 70\%-97\% of cases, with many reports $\sim 90 \% .{ }^{10}$ Our results are higher than those of the pediatric eye disease investigator group in 2009 in a study that included 955 eyes of 718 children aged 6 months to $<48$ months, who underwent initial probing. The success rate was $78 \%$ overall and was $78 \%$ for children aged 6 months to $<12$ months, $79 \%$ for children aged 12 months to $<24$ months, $79 \%$ for children aged 24 months to $<36$ months, and $56 \%$ for children aged 36 months to $<48$ months. ${ }^{11}$ Results are higher than those of the study by Casady et $\mathrm{al}^{12}$ that included 127 patients, ranging in age from 1 month to 81 months, with 173 lacrimal systems diagnosed with CNLDO that were treated with initial probing showing a success rate of $76.9 \%$.

Multiple studies have been carried out to assess the role of intubation as a primary treatment for CNLDO, to our knowledge none of them was a case-controlled study.,12 Success in the intubation group was achieved in $83.3 \%$ of cases (25 cases). This success is comparable with that of the original designer of the Masterka tube, Fayet et al, ${ }^{13}$ in a study that assessed the role of pushed MCI using the Masterka tube as a primary management of CNLDO; the trial included 110 eyes, and success was achieved in 94 eyes (85\%).

Eshraghi et $\mathrm{al}^{14}$ in a prospective study assessed the role of pushed MCI in children with complex CNLDO, they found complete resolution in 26 of 44 eyes (59.1\%).

Comparing our results with those of other trials that assessed the role of silicon intubation in primary management of CNLDO but with a different type of tube showed that our success rate is less than that reported by the pediatric eye disease investigator group in 2008 in a nonrandomized noncomparative trial that included 182 eyes of children between 6 months and 48 months. They found that intubation is successful as a primary management in $90 \%$ of cases, in which MCI was used in $70 \%$ of cases. ${ }^{15}$ Engel et $\mathrm{al}^{8}$ reported in a retrospective case series of 635 patients in whom they found an overall success rate of $96 \%$, which showed a decline to $90 \%$ in patients older than 24 months.

This difference in success rate could be attributed to the larger number of cases or different types of tubes used. Kaufman and Guay-Bhatia ${ }^{6}$ showed in a retrospective study on 50 eyes treated with MCI with the Monoka tube (36 as primary treatment) with an overall success rate of $79 \%$.

We have noted that the outcome of the nasolacrimal duct probing at 1 week follow-up was an indication of the final outcome, which was also noted by Kashkouli et al. ${ }^{7}$
Probing has commonly been advised as an initial interventional treatment of congenital nasolacrimal duct obstruction (CNDO), after conservative treatment failures..$^{3,16-19}$ Recently, however, some authors prefer to stent all patients at initial probing, regardless of complexity as it is thought to be associated with a high success and a low complication rate. ${ }^{8}$ Silicon intubation has been recommended by some authors as the primary procedure in patients who are older than 18-24 months, because of the presumed reduced success rate of probing with age. ${ }^{4}$ Also, a small proportion of newborns with CNLDO have anatomical variations that are unlikely to resolve spontaneously or be relieved by simple probing. ${ }^{10}$

Advocates of primary intubations see that probing may induce minor injuries to the lacrimal duct epithelium, which may lead to cicatricial stricture and prevent the resolution of CNDO. ${ }^{1}$ When probing fails, iatrogenic canalicular obstructions occur in $44 \%$ of cases. ${ }^{20}$ The silicone tube may prevent the formation of granulation-related obstruction around the recent tract. ${ }^{21,22}$

Bleeding could be observed during probing, which might be a sign of trauma further down the system, or a false passage formation. ${ }^{1}$ It occurs in $20 \%$ of cases. ${ }^{1,23}$ In our study, bleeding from the punctum occurred in $23.3 \%$ of probing and $10 \%$ of intubation group.

Another problem is the lower success rate of probing with older children. ${ }^{14,23-25}$ Katowitz and Welsh ${ }^{24}$ advocated probing for patients' younger than 13 months as they found that probing before 13 months had a cure rate of $97 \%$, which was reduced to $54.7 \%$ after 13 months of age. However, some studies have suggested that probing maintains a high success rate without any age-related decline. ${ }^{2,23,25}$ Upon comparing the effect of age of our patients with success in both groups, there was no statistical significance. The amount of failed cases in our study was small for a meaningful statistical assessment of an age effect.

To overcome the above problems, we assessed a new type of stenting technique, the Masterka, which offers an exciting alternative that can be done with masked ventilation alone.

Different types of intubation system are present, bicanalicular intubation and MCI. The Masterka offers a MCI.

In this study, we inserted the monocanalicular tube into the superior canaliculus, we observed a single case of corneal abrasion (2.8\%) few days after the surgery, the abrasion was central and healed in 3 days without the need of early removal of the tube. Fayet et $\mathrm{al}^{26}$ deduced that placing the MCI in the superior canaliculus could be a cause of corneal irritation especially if the collaret has a large size. However, 
Engel et $\mathrm{al}^{8}$ recommend placing the tube into the superior canaliculus. $^{8}$

We had one case of lost tube before the intended time of removal; premature removal of tube may result in the recurrence of obstruction. ${ }^{8,15,27,28}$

Advantages of the pushed MCI include the type of anesthesia used and no retrieval of the tube is required from the nose, thus insertion can be done only with masked airway anesthesia. However, a "pulled", monocanalicular (selfthreading) stent requires general anesthesia and laryngeal protection for retrieval of the stent from the nose.

In our study, we were able to insert the tube in selected cases (three cases) under sedation only using chloral hydrate as an outpatient procedure without the need for admission to the surgical facility.

Another advantage is the simplicity of insertion compared with other monocanalicular and bicanalicular tubes; the use of a pushed intubation method resembles a simple probing technique more than does the pulled intubation. Applying the tube into one canaliculus only has an advantage of reducing the risk of iatrogenic trauma to the lacrimal system, ${ }^{29}$ and the tube is fixated in the punctum without the need of anchoring sutures, there is no risk of cheese wiring of the puncta due to excessive tension as in cases of bicanalicular intubation. ${ }^{28,29}$ Finally, removal of the tube is simple and done under light sedation as an office procedure.

One of the main drawbacks of the use of Masterka for treatment is that it is only effective for simple mucosal obstructions of the nasolacrimal duct, unlike other types of silicon intubations. Complex cases with a stenotic nasolacrimal duct are determined by absence of metallic contact, difficulty during insertion of the tube, and the silicon bunches up around the introducer without passing the stenosis, if this is found then the Masterka is not indicated.

Another problem is that with pushed intubation, removal of the metallic guide by the upper approach will not correct the false passage, whereas with pulled intubation some cases of false passage can be corrected to a certain extent, during retrieval of the stent by the lower nasal approach. This may be reduced by detecting the metallic contact within the nasal fossa to confirm the presence of a ductal opening below the inferior turbinate.

The major obstacle for recommended routine use for primary treatment is the cost of the Masterka. Both intubation and probing are performed in a surgical facility under mask ventilation anesthesia. The tubes currently cost the facility $\sim \$ 70$, whereas the probing does not require this extra cost. In addition, intubation requires a visit to remove the tubes, but this is done in the office and does not need a surgical facility.

\section{Conclusion}

Although there was no statistical difference in the success rate of probing and Pushed Monocanalicular intubation, it is an effective way in the management of nasolacrimal duct obstruction and it requires only mask inhalation anesthesia and it is a good alternative for treatment with low complication rate.

\section{Acknowledgments}

Preliminary results of this work have been presented as a poster in ESOPRS meeting in Barcelona, Spain, September 2013. No financial support was received for this submission.

\section{Disclosure}

The authors report no conflicts of interest in this work.

\section{References}

1. Young JD, MacEwen CJ. Managing congenital lacrimal obstruction in general practice. $B M J .1997 ; 315(7103): 293-296$.

2. MacEwen CJ, Young JD. Epiphora during the first year of life. Eye. 1991;5(pt 5):596-600.

3. Stevens JL. Success rates of nasolacrimal duct probing at time intervals after 1 year of age (Discussion). Ophthalmology. 1998;105(7): 1309-1310.

4. Paul TO, Shepherd R. Congenital nasolacrimal duct obstruction: natural history and the timing of optimal intervention. J Pediatr Ophthalmol Strabismus. 1994;31(6):362-367.

5. Takahashi T, Kakizaki H, Chan W, Selva D. Management of congenital nasolacrimal obstruction. Acta Ophthalmol. 2010;88(5):506-513.

6. Kaufman LM, Guay-Bhatia LA. Monocanalicular intubation with Monoka tubes for the treatment of congenital nasolacrimal duct obstruction. Ophthalmology. 1998;105(2):336-341.

7. Kashkouli MB, Kempster RC, Galloway GD, Beigi B. Monocanalicular versus bicanalicular silicone intubation for nasolacrimal duct stenosis in adults. Ophthal Plast Reconstr Surg. 2005;21(2):142-147.

8. Engel JM, Hicuje-Schmidt C, Khammar A, Ostfeld BM, Vyas A, Ticho BH. Monocanalicular silastic intubation bor the initial correction of congenital nasolacrimal duct obstruction. J AAPOS. 2007;11(2): 183-186.

9. Munk PL, Lin DT, Morris DC. Epiphora: treatment by means of dacryocystoplasty with balloon dilatation of the nasolacrimal drainage apparatus. Radiology. 1990;177(3):687-690.

10. Skuta G, Cantour L, Weiss J. Section 6: Pediatric Ophthalmology and Strabismus. San Francisco, CA: American Academy of Ophthalmology, BCSC; 2011.

11. Pediatric Eye Disease Investigator Group; Repka MX, Chandler DL, Bremer DL, Collins ML, Lee DH. Repeat probing for treatment of persistent nasolacrimal duct obstruction. JAAPOS. 2009;13(3): 306-307.

12. Casady DR, Meyer DR, Simon JW, Stasior GO, Zobal-Ratner JL. Stepwise treatment paradigm for congenital nasolacrimal duct obstruction. Ophthal Plast Reconstr Surg. 2006;22(4):243-247.

13. Fayet B, Katowitz W, Racy E, Ruban JM, Katwowitz J. Pushed monocanalicular intubation: an alternative stenting system for the management of congenital nasolacrimal obstructions. J AAPOS. 2012;16(5): $1-5$. 
14. Eshraghi B, Aghajani A, Kasaei A, Tabatabaei Z, Akbari M, Fard MA. "Pushed" stent intubation for treatment of complex congenital nasolacrimal duct obstruction. Eur J Ophthalmol. 2014;24(5):650-654.

15. Pediatric Eye Disease Investigator Group; Repka MX, Melia BM, et al. Primary treatment of nasolacrimal duct obstruction with nasolacrimal duct intubation in children younger than 4 years of age. J AAPOS. 2008; 12(5):445-450.

16. Cassady JV. Dacryocystitis of infancy. Am J Ophthalmol. 1948;31(7): 773-780

17. Cassady JV. Developmental anatomy of nasolacrimal duct. Arch Ophthalmol. 1952;47(2):141-158.

18. Koke MP. Treatment of occluded nasolacrimal ducts in infants. Arch Ophthalmol. 1950;43(4):750-754.

19. Robb RM. Probing and irrigation for congenital nasolacrimal duct obstruction. Arch Ophthalmol. 1986;104(3):378-379.

20. Lyon DB, Dortzbach RK, Lemke BN, Gonnering RS. Canalicular stenosis following probing for congenital nasolacrimal duct obstruction. Ophthalmic Surg. 1991;22:228-232.

21. Dortzbach RK, France TD, Kushner BJ, Gonnering RS. Silicone intubation for obstruction of the nasolacrimal duct in children. $\mathrm{Am}$ J Ophthalmol. 1982;94(5):585-590.

22. Kapadia MK, Freitag SK, Woog JJ. Evaluation and management of congenital nasolacrimal duct obstruction. Otolaryngol Clin North Am. 2006;39(5):959-977.
23. Kashkouli MB, Beigi B, Parvaresh MM, Kassaee A, Tabatabaee Z. Late and very late initial probing for congenital nasolacrimal duct obstruction: what is the cause of failure? Br J Ophthalmol. 2003;87(9): 1151-1153.

24. Katowitz JA, Welsh MG. Timing of initial probing and irrigation in congenital nasolacrimal duct obstruction. Ophthalmology. 1987;94(6): 698-705.

25. Honavar SG, Prakash VE, Rao GN. Outcome of probing for congenital nasolacrimal duct obstruction in older children. Am J Ophthalmol. 2000; 130(1):42-48.

26. Fayet B, Hurbli T, Renard G, Ruban JM, Racy E, Bernard JA. Suggested precautions when using a monocanalicular stent. Ophthal Plast Reconstr Surg. 2001;17(1):76-77.

27. Al-Hussain H, Nasr AM. Silastic intubation in congenital nasolacrimal duct obstruction: a study of 129 eyes. Ophthal Plast Reconstr Surg. 1993; 9(1):32-37.

28. Fayet B, Bernard JA, Assouline M. Bicanalicular versus monocanalicular silicone intubation for nasolacrimal duct impotency in children: a comparative study. Orbit. 1993;12:149-156.

29. Komínek P, Červenka S, Pniak T, Zeleník K, Tomášková H. Monocanalicular versus bicanalicular intubation in the treatment of congenital nasolacrimal duct obstruction. Graefes Arch Clin Exp Ophthalmol. 2011;249(11):1729-1733.
Clinical Ophthalmology

\section{Publish your work in this journal}

Clinical Ophthalmology is an international, peer-reviewed journa covering all subspecialties within ophthalmology. Key topics include: Optometry; Visual science; Pharmacology and drug therapy in eye diseases; Basic Sciences; Primary and Secondary eye care; Patient Safety and Quality of Care Improvements. This journal is indexed on

Submit your manuscript here: http://www.dovepress.com/clinical-ophthalmology-journal

\section{Dovepress}

PubMed Central and CAS, and is the official journal of The Society of Clinical Ophthalmology (SCO). The manuscript management system is completely online and includes a very quick and fair peer-review system, which is all easy to use. Visit http://www.dovepress.com/ testimonials.php to read real quotes from published authors. 